\title{
Comparative Evaluation of Lip Prints Patterns in Gender and Different Musculoskeletal Malocclusion
}

Dr. Sandhya Jain, Dr. Arwa Saifee*

Prof and Head of Department of Orthodontics, Govt. College of Dentistry, Indore, India

\author{
DOI: $\underline{10.36348 / \text { SJODR.2019.v04i10.008 }}$ \\ | Received: 09.10.2019| Accepted: 16.10.2019| Published: 29.10.2019
}

*Corresponding author: Dr. Arwa Saifee

\section{Abstract}

Aims: To determine association between lip print pattern and different skeletal malocclusions and gender: Material and Methods: Lip prints of 250 patients were obtained and analyzed. Skeletal and dental class I, II, III were analyzed and gender were mentioned. Kruskal wallis test was applied and p value was derived. Level of significance was kept at .05\%. Results: In skeletal Class I Males, type IV lip print is common; while in class I females IV are most common. In skeletal Class II males, Type IV. However in Class II females - Lip print type II is most common. In skeletal class III males Type I lip print is more common and class III Females Type II lip print is commonest. Conclusion: There exists a particular pattern of Lip prints in certain skeletal malocclusion and gender. Aims and objectives: To analyze the association of different lip print patterns in different skeletal malocclusion and gender and derive a relation between the two.

Keywords: Comparative Evaluation, Musculoskeletal Malocclusion, Lip prints. Copyright @ 2019: This is an open-access article distributed under the terms of the Creative Commons Attribution license which permits unrestricted
use, distribution, and reproduction in any medium for non-commercial use (NonCommercial, or CC-BY-NC) provided the original author and source
are credited.

\section{INTRODUCTION}

One of the most difficult things since a long time is the identity of individuals. It is required for many reasons like personal, financial, dispute over biological parents, identification of dead bodies and also importantly legal aspects [1]. Characteristics which are unique are used to identify people. One common example is finger prints. It is permanent, unique and reliable source of human identification.

A similar style for identification also occurs lip prints. These are defined as normal lines or wrinkles in the zone of transition of human lip, (called sulci labiorum), study of which is called cheiloscopy.

It can be defined "as a method of identification of a person based on characteristic arrangements of lines appearing on the red part of lips or as a science dealing with lines appearing on red part of the lips".

The relationship between the skeletal malocclusions (Class I, II and III) and soft tissue facial morphology has been an arena of vast research in contemporary orthodontics. The lip prints are unique to an individual just like the fingerprints and shows strong hereditary pattern. Therefore; this study was designed to explore correlation of lip prints with skeletal base relationship in North Indian adult population and if possible, to establish lip prints as relevant diagnostic and forensic tool $[2,3]$.

Advantages of considering lip prints as a reliable identification source-

- It remains uniform throughout the life.

- Can be used to predict certain traits such as malocclusion.

\section{CLASSIFICATION}

In 1967 Santos was the first person to classify lip grooves. He divided them in to four types namely[4]

- Straight line

- Curved line

- Angled line

- Sine-shaped line

Suzuki and Tsuchihashi, in 1970, devised a classification method of lip prints, which follows[4]: 


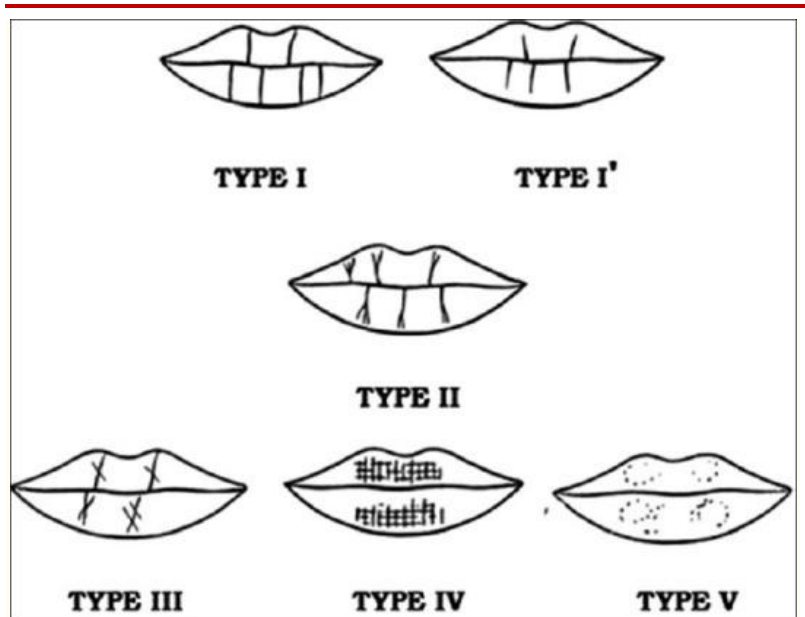

Fig-1: Suzuki and Tsuchihashi classification

- Type I: A clear-cut groove running vertically across the lip.

- $\quad$ Type I': Partial-length groove of Type I.

- Type II: A Branched groove.

- Type III: An intersected groove.

- Type IV: A Reticular pattern

- Type V: Other patterns.

This classification is the most commonly used for recording the pattern on the lips.

Lip prints can be recorded in a number of ways.

- Photographing the suspect's lips.

- On a non-porous flat surface such as a mirror they can be photographed, enlarged and overlay tracings made of the grooves.

- Applying lipstick, lip rouge, or other suitable transfer mediums to the lips and then having the individual press his or her lips to a piece of paper or cellophane tape or similar surface.

- Using a finger printer, preferably a roller finger printer.

- By having the subject impress his or her lips (without lipstick or other recording medium) against a suitable surface and then processing these prints with either conventional finger print developing powder or with a magna brush and magnetic powder.

\section{MATERIAL AND METHODS}

Sample included 250 Central Indian population, adult subjects. The study was conducted in Government college of dentistry, Indore, in department of orthodontics and Dentofacial Orthopedics. Subjects were randomly chosen from the outpatient department. Criteria for sample selection included subjects having no lesions on the lips, no congenital facial defects, no congenitally missing teeth or extracted teeth (except third molars). Individuals with known hypersensitivity to lipsticks were not included in this study and none of the subjects had undergone orthodontic treatment or maxillofacial surgery previously. A written informed consent was obtained from all the subjects.

The lip prints were obtained by applying lipstick and then individual pressing his/ her lips against cellophane tape. This was then transferred to a thick paper sheet and then used to analyze the lip pattern. (figure 1). Suzuki and Tsuchihashi's classification was followed. It was modified by the author as more than one lip print patterns are seen to be existing in single lip. Thus the lip was divided in two parts - upper and lower lip. tlupper lip was divided in three parts by vertical lines passing through mid-line and sides.(figure 2). Similarly, lower lip was divided. Each of the segment was then evaluated for lip patterns. Pattern which was existing in more than $75 \%$ of lip was assigned that pattern

Also, the molar relation and skeletal pattern obtained through cephalometric evaluation was checked in these patients and recorded.

Data collected was analyzed and segregated and prepared a chart. Statistics were applied to the data.

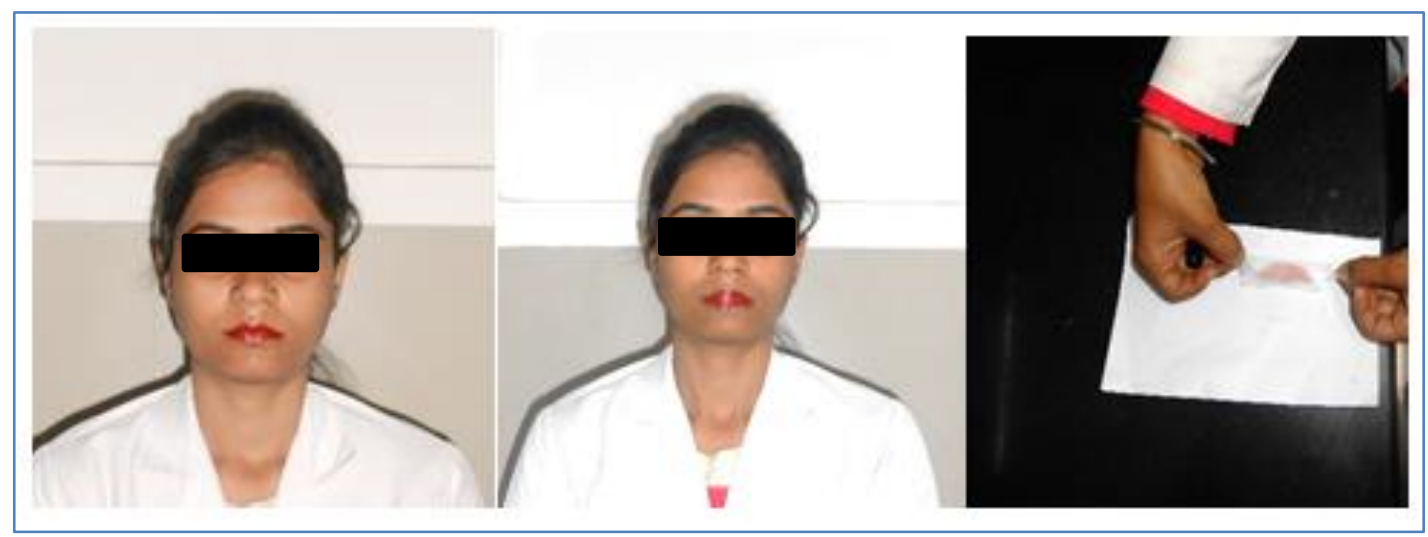

Fig-1: Method of taking lip prints 


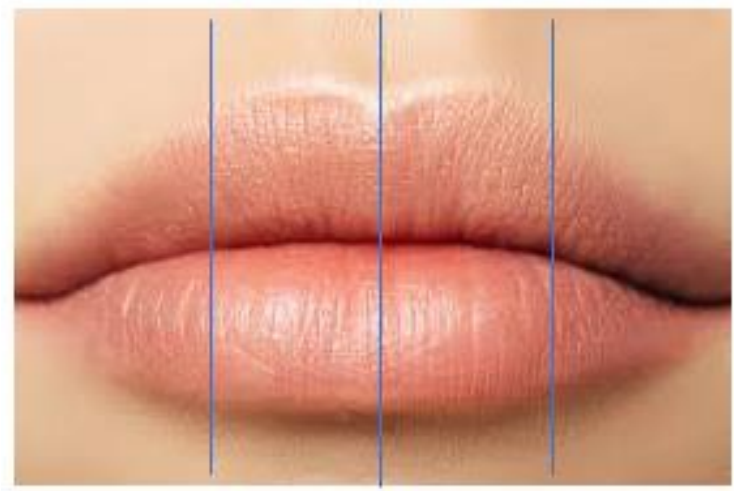

Fig-2: Division of lips in 8 zones

\section{Observations}

Table-1: Demographic details of malocclusion and Gender with lip prints patterns

\begin{tabular}{|l|l|l|l|l|l|l|l|l|}
\hline $\begin{array}{l}\text { Lip } \\
\text { prints }\end{array}$ & $\begin{array}{l}\text { Class 1 } \\
\text { Males }\end{array}$ & $\begin{array}{l}\text { Class 1 } \\
\text { Females }\end{array}$ & $\begin{array}{l}\text { Class II } \\
\text { Males }\end{array}$ & $\begin{array}{l}\text { Class II } \\
\text { Females }\end{array}$ & $\begin{array}{l}\text { Class III } \\
\text { Males }\end{array}$ & $\begin{array}{l}\text { Class III } \\
\text { Females }\end{array}$ & $\begin{array}{l}\text { Kruskal } \\
\text { wallis test X }\end{array}$ & significance \\
\hline I & 9 & 21 & 5 & 3 & 3 & 1 & .001 & significant \\
\hline I' & 8 & 1 & 9 & 1 & 2 & 0 & .02 & Non-significant \\
\hline II & 6 & 12 & 8 & 30 & 1 & 3 & .001 & significant \\
\hline III & 12 & 08 & 8 & 7 & 1 & 0 & .003 & significant \\
\hline IV & 21 & 24 & 15 & 6 & 0 & 1 & .001 & Significant \\
\hline V & 9 & 5 & 8 & 3 & 0 & 0 & .03 & Non-significant \\
\hline
\end{tabular}

According to table 1, in each group i.e. skeletal Class I Males, type IV lip print is common; while in class I females IV is most common. In skeletal Class II males, Type IV.
However in Class II females - Lip print type II is most common. In skeletal class III males Type I lip print is more common and class III Females Type II lip print is commonest.

Table-2: Distribution of lip prints patterns in skeletal malocclusion

\begin{tabular}{|l|l|l|l|}
\hline Lip prints & Skeletal Class 1 & Skeletal Class II & Skeletal Class III \\
\hline I & 30 & 8 & 4 \\
\hline I & 9 & 10 & 2 \\
\hline II & 36 & 40 & 3 \\
\hline III & 20 & 9 & 1 \\
\hline IV & 39 & 14 & 1 \\
\hline V & 13 & 10 & 0 \\
\hline
\end{tabular}

Table-3: Percentage of lip prints in males and females

\begin{tabular}{|l|l|l|l|}
\hline Patterns & Males (\%) & Females (\%) & P value \\
\hline Type I & $17(13.6 \%)$ & $53(43.3 \%)$ & 0.0001 \\
\hline TYPE I' & $9(7.2 \%)$ & $37(30.6 \%)$ & .0001 \\
\hline TYPE II & $15(12 \%)$ & $18(14.17 \%)$ & .05 \\
\hline TYPE III & $21(16.8 \%)$ & $8(5.29 \%)$ & .007 \\
\hline TYPE IV & $36(28.8 \%)$ & $6(4.14 \%)$ & .0001 \\
\hline TYPE V & $27(21.9 \%)$ & $4(2.5 \%)$ & .0001 \\
\hline
\end{tabular}

\section{RESULTS}

After applying chi square test, Statistics value - chi square value - 24.71 and $p$ value obtained is highly statistically significant $-p=0.00$. Thus there is difference in malocclusion and lip print patterns.

In each group i.e. skeletal Class I Males, type IV lip print is common; while in class I females IV is most common. In skeletal Class II males, Type IV. However in Class II females - Lip print type II is most common. In skeletal class III males Type I lip print is more common and class III Females Type II lip print is commonest (table 2).

According to results shown in table 3 in this study type I and I' is more common in females followed by type II lip pattern. In males most predominant lip pattern type IV followed by type V. Statistical analysis shows significant $p$ value, thus showing sexual dimorphism in lip print patterns.

\section{DISCUSSION}

Present study reveals that different malocclusions had certain predominant lip print patterns. For example - in skeletal class I, lip prints IV and II are predominantly present. In class II, lip pattern 
that is predominant is type II. In class III, predominant lip pattern is type I.

While in gender, type I and I' is more commonly seen lip patterns in females while Type IV and $\mathrm{V}$ are common in males.

T R Saraswathi et al. [5] in 2009 published a study on variation of morphological lip print pattern in males and females; his results showed that Type III lip pattern is most prevalent in both males and females in South Indian population.

In another recent study conducted by Ezemagu et al. [6] in 2018, found Type I' is most predominant pattern in Males and type $\mathrm{I}$ is most common in Females.

However, in present study Type IV is most common lip pattern seen in males and type I is most commonly seen in females.

Narayan et al. [7] in 2012 conducted study to analyse relation of malocclusion to lip prints and his results show that lip pattern type I and III are more common in Skeletal Class I; Type I and IV are more common with skeletal class III, and type I and II being more common with skeletal class II.

In a similar study by P Raghav et al. in 2013 [8], to explore the association of lip print and malocclusion in north Indian population, concluded that no sexual dimorphism was present and that vertical lip pattern was predominant in skeletal class III malocclusion.

\section{CONCLUSION}

Thus lip prints can be employed for sagittal jaw relation recognition which may be of great help in identification to forensic people. Also in our study, it has shown to have sexual dimorphism present. But still further extensive studies with larger sample size are necessary to be carried out to establish a clear cut association between the two.

\section{REFERNCES}

1. Amith, H.V., Ankola, A.V., Nagesh, L.(2011). Lip prints-can it aid in individual identification. J Oral Health Comm Dent, 5:113-8.

2. Reddy, L.V.(2011). Lip prints: An overview in forensic dentistry. J Adv Dental Research, 2:17-20.

3. Bajpai, M., Mishra, N., Yadav, P., Kumar, S. (2011). Efficacy of lip prints for determination of sex and inter observer variability. Euro J Exp Bio, 1:81-6.

4. Prabhu, R. V., Dinkar, A. D., Prabhu, V. D., \& Rao, P. K. (2012). Cheiloscopy: revisited. Journal offorensic dental sciences, 4(1), 47-52.

5. Saraswathi, T.R., Mishra, G., Ranganathan, K. (2009). Study of lip prints. Journal of forensic dental sciences, Jan 1;1(1):28.

6. Kenneth, E.U., Emelda, O.C, Obaje, S.G, Chinedu, U.G.(2018). European Journal of Biomedical AND Pharmaceutical science.s. European Journal of Biomedical, 5(10):379-84.

7. Kulkarni, N., Vasudevan, S., Shah, R., Rao, P., \& Balappanavar, A. Y. (2012). Cheiloscopy: A new role as a marker of sagittal jaw relation. Journal of forensic dental sciences, 4(1), 6-12.

8. Raghav, P., Kumar, N., Shingh, S., Ahuja, N.K., Ghalaut, P. (2013). Lip prints: The barcode of skeletal malocclusion. Journal of forensic dental sciences. Jul;5(2):110. 